\title{
Morphometric analysis of the palmaris longus muscle: a fetal study
}

\author{
Necdet Kocabıyı, Selda Yıldız, Sedat Develi, Hasan Ozan, Fatih Yazar \\ Department of Anatomy, Gulhane Military Medical Academy, Ankara, Turkey
}

\begin{abstract}
Objectives: The palmaris longus muscle is absent in 10-15\% of forearms. Its long, flat tendon broadens as it passes in front of flexor retinaculum, to which it is partly adherent. In the palm it splits to attach the longitudinally directed fibres of the palmar aponeurosis. This fetus study is made to evaluate morphometric and topographic differences of adult and fetal palmaris longus muscle.

Methods: The present study is carried out on 24 human fetuses aged 17-40 weeks of gestation. All upper limbs were carefully dissected with the aid of a stereomicroscope at 1.6x magnification. Digital calliper was used for all the measurements. Results: The palmaris longus muscles were absent in both forearms in 7 fetuses and in a unilateral forearm in 5 fetuses. Reversed palmaris longus muscle was found in 2 forearms. Most fetuses had a typical palmaris longus muscle and tendon shape. The mean length and width of the tendons were $18.42 \pm 9.55$ and $0.66 \pm 0.37 \mathrm{~mm}$, respectively, in second trimester and, $25.9 \pm 13.90$ and $1.71 \pm 0.95 \mathrm{~mm}$ in third trimester, respectively. The mean length and width of the muscular belly were $13.33 \pm 7.05$ and $2.03 \pm 1.04 \mathrm{~mm}$, respectively, in second trimester and, $30.42 \pm 16.81$ and $3.77 \pm 2.07 \mathrm{~mm}$ in third trimester, respectively.

Conclusion: The results of our study show to more pronounced loss of the muscle on the left side. This detailed fetal study in relationship to the palmaris longus muscle would be useful for educational anatomy dissections and surgical interventions for relevant clinical procedures.
\end{abstract}

Key words: agenesis; fetus; morphologic evaluation; palmaris longus muscle; tendon variations

Anatomy 2012-2013;6-7:42-47, (c) 2012-2013 TSACA

\section{ntroduction}

The palmaris longus is a slender, fusiform muscle medial to flexor carpi radialis. It springs from the medial epicondyle by the common tendon, and from adjacent intermuscular septa and deep fascia. It converges on a long tendon, which passes anterior (superficial) to the flexor retinaculum. A few fibres leave the tendon and interweave with the transverse fibres of the retinaculum, but most of the tendon passes distally. As the tendon crosses the retinaculum it broadens out to become a flat sheet which becomes incorporated into the palmar aponeurosis. The tendon lies in front of the median nerve just above the wrist. The palmaris longus is sometimes absent on one or both sides. Most standard textbooks report on the rate of palmaris longus muscle absence of $15 \% .^{[1-3]}$ The palmaris longus muscle is extremely variable in both number and form. ${ }^{[4]}$

The variations of the palmaris longus muscle were classified by Schlafly and Lister in five groups: classical, double, reverse, central and bifid. ${ }^{[5]}$ Reversed palmaris longus muscle means that the palmaris longus muscle was tendinous in its upper part and muscular in its lower part. Rarely, the reversed muscle belly can be two or three-headed. ${ }^{[4]}$

It is well known that individuals may have unilateral or bilateral absence of palmaris longus. This structure is often used in reconstructive plastic surgery mainly in the setting of tendon grafting, by the way it has also been used for a wide variety of procedures including lip augmentation, ptosis correction and in the management of facial paralysis. ${ }^{[6]}$ 
Many surgeons agree that the palmaris longus tendon is the first choice as a donor tendon because it fulfills the necessary requirements of the length, diameter and availability, and can be used without producing any functional impairment. ${ }^{[7]}$ Palmaris longus is the best choice for use in the palm-to-fingertip graft because it is located in the same field of surgery and is easily accessible. ${ }^{[8]}$ The functional dynamics of the muscle and the clinical implication of its modifications in humans and fetuses are discussed. ${ }^{[9]}$

Although there is enough information about adult palmaris longus in the literature, there is a lack of knowledge about human fetuses. Therefore, our study aimed to evaluate morphometric, topographic and developmental differences between adult and fetal palmaris longus and to support additional information for clinical procedures.

\section{Materials and Methods}

The present study was carried out on 24 human fetuses (17 male, 7 female) aged 17-40 weeks of gestation with no external pathology or anomaly. The weeks between first and 13 th were accepted as first trimester, 14th-27th as second and 27th-40th as third. None of fetuses was in the first trimester. Approval of ethics committee was obtained from the Ethics Committee of Gulhane Military Medical Academy with file number 1491-1380-11/1539. Each macroscopic dissection was carried out according to the following protocol. A longitudinal cutaneous incision was made in line with the fourth finger from the medial aspect of the elbow region to the palm. Initially, only the skin was dissected and raised medially and laterally to display the subcutaneous tissue. Then subcutaneous tissue and the antebrachial fascia was carefully removed to expose the palmar aponeurosis with the aid of a Carl-Zeiss OPMI 1-
FR stereomicroscope at 1.6x magnification (Carl Zeiss Microscopy GmbH, Göttingen, Germany). We measured the length and width of the tendinous portion and muscular belly of the palmaris longus in human fetuses. All measurements were made with digital calliper (Mitutoyo Solar Absolute Digimatic Calliper, Mitutoyo Corporation, Kawasaki, Kanagawa, Japan). The tendon length of the palmaris longus muscle was evaluated from the bistyloid line to musculotendineus junction. Bistyloid line is the distance between the lateral side of the tip of the styloid process of the radius and the medial side of the tip of the styloid process of the ulna. The length of the muscular belly evaluated from interepicondylary line to musculotendineus junction. The width of the tendon and the muscular belly measured from the midpoint.

Means and standard deviations of these measurements were calculated. All statistical analysis was done using SPSS. Chi-square test was used to evaluate the relationship between gender and absence of extremity; the dashed data. After evaluation of distrubition with Kolmogorov-Smirnov test in datas such as muscle (muscular belly/venter) and tendon lengths student-t test or Mann-Whitney $\mathrm{U}$ test made.

\section{Results}

We investigated the morphometry and the absence of the palmaris longus muscle in human fetuses. The palmaris longus muscles were absent in both forearms in 7 and in one forearm in 5 fetuses. Most fetuses had a typical palmaris longus muscle and tendon shape (Figure 1). The mean length and width of the tendons in second trimester were $18.42 \pm 9.55$ and $0.66 \pm 0.37 \mathrm{~mm}$, respectively, and, $25.9 \pm 13.90$ and $1.71 \pm 0.95 \mathrm{~mm}$ in third trimester, respectively. The mean length and width of the muscular belly in second trimester were $13.33 \pm 7.05$

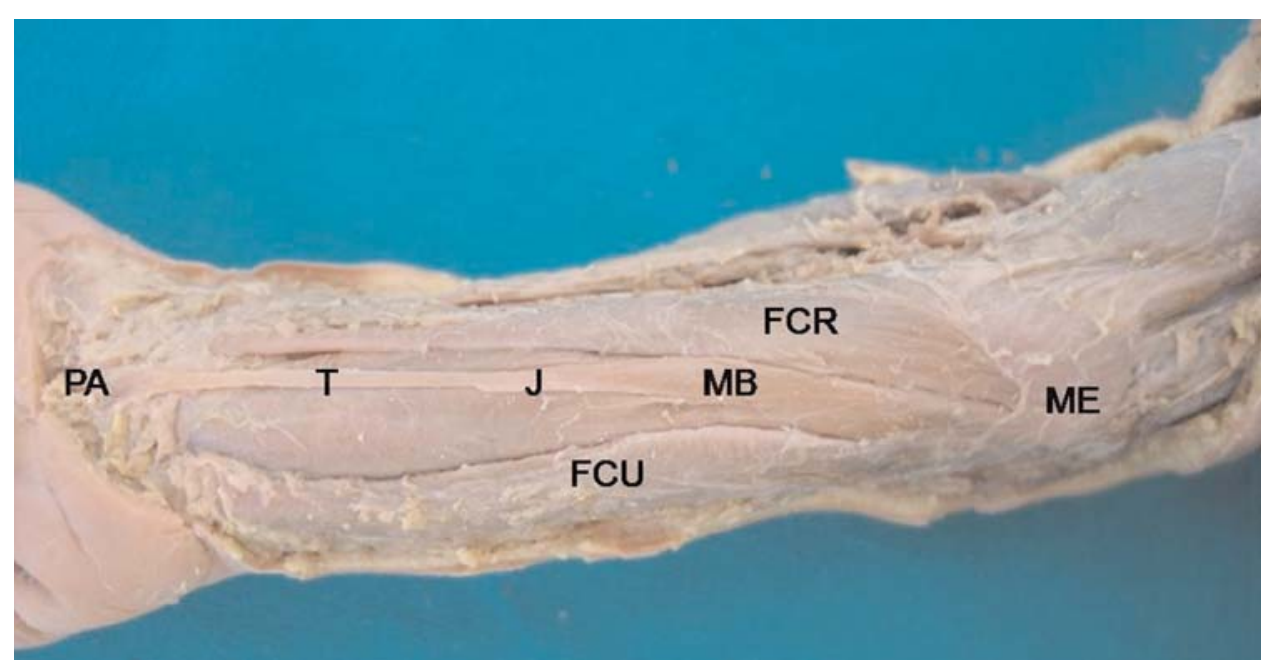

Figure 1. Right forearm. A typical palmaris longus muscle and tendon shape. T: tendon of palmaris longus; MB: muscular belly of palmaris longus; ME: medial epicondyl; PA: palmar aponeurosis; J: musculotendineous junction; FCU: flexor carpi ulnaris; FCR: flexor carpi radialis. 
and $2.03 \pm 1.04 \mathrm{~mm}$, respectively, and, $30.42 \pm 16.81$ and $3.77 \pm 2.07 \mathrm{~mm}$ in third trimester, respectively (Figures 2 and 3, Table 1).

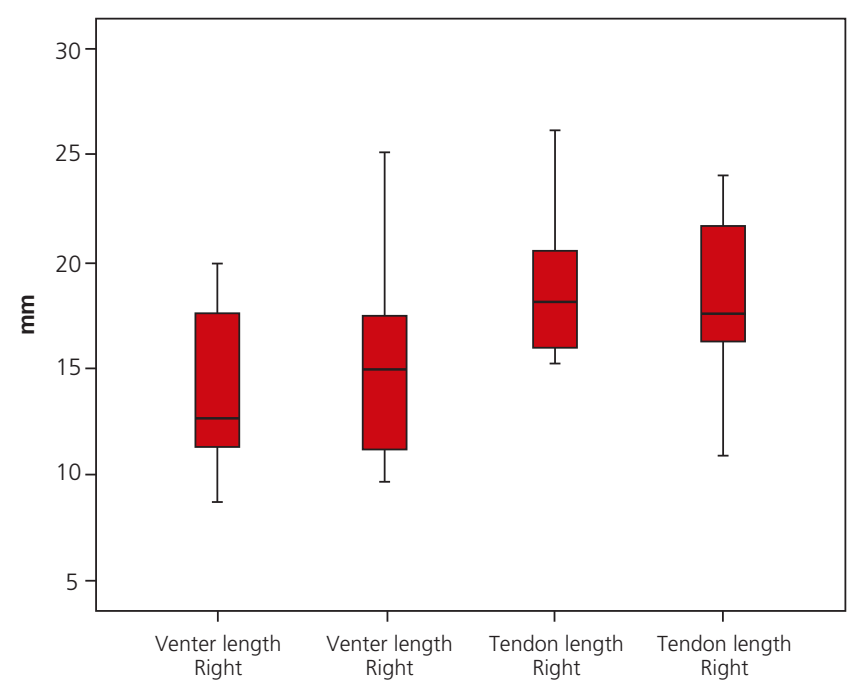

Figure 2. Lengths of the muscular bellies/venter and tendons.

Reversed palmaris longus muscle was found in 2 forearms in two fetuses (Figure 4). Long muscular belly and short tendon of palmaris longus muscle was observed in one of 24 fetuses but in both forearms (Figure 5).

\section{Discussion}

The palmaris longus is often described as one of the most variable muscles in the human body and is classified as a phylogenetically retrogressive muscle i.e. a short belly with a long tendon. ${ }^{[10]}$ In vertebrates it exists only in mammals and is best developed in those where the forelimb is used for ambulation. ${ }^{[11]}$
The most common variations are: duplication (two origins and two insertions), digastric (with proximal and distal bellies), reversed (muscle belly arising from the

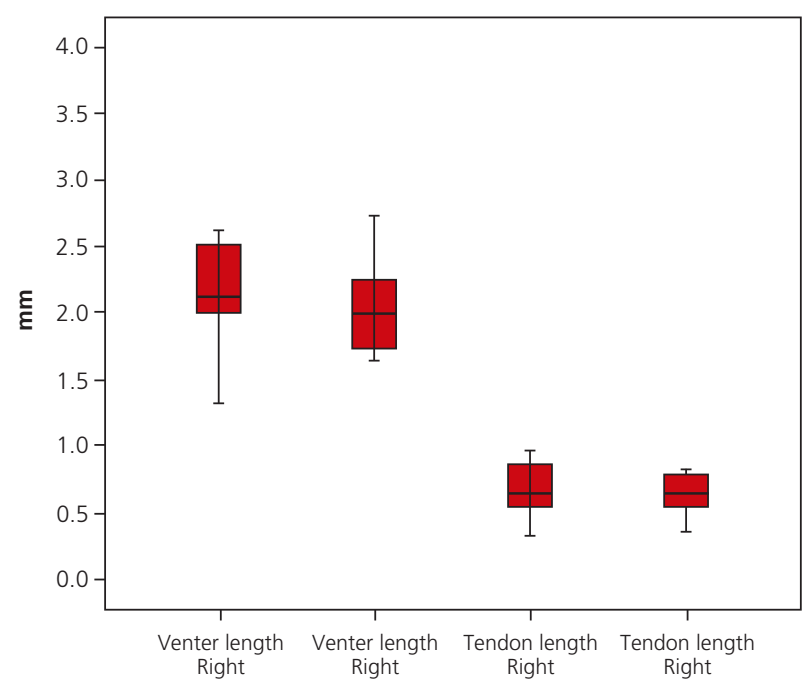

Figure 3. Widths of the muscular bellies/venter and tendons.

palmar aponeurosis, with proximal tendon), and a bifid reversed variation (proximal tendon and distal bifid muscle belly). ${ }^{[5]}$

The prevalence of the agenesis of this muscle is reported about $15 \%$ in most classical anatomy textbooks. ${ }^{[1-3]} \mathrm{A}$ higher prevalence (24\%) was reported in North American Caucasians. ${ }^{[7]}$ A survey in Pennsylvania, USA, showed $23 \%$ prevalence of absence. ${ }^{[12]}$ Kayode et al. reported in Nigerian population $31.25 \%$ (187 subjects) lack palmaris longus muscle on either of the forearms. $12.5 \%$ (75 subjects) showed unilateral absence and $18.75 \%$ (112 subjects) showed bilateral absence. ${ }^{[13]}$ Ceyhan and Mavi

Table 1

Descriptive statistics

\begin{tabular}{|c|c|c|c|c|c|}
\hline & $\mathbf{N}$ & Minimum & Maximum & Mean & Std. Deviation \\
\hline Muscular belly L-right & 17 & 7.57 & 39.52 & 16.53 & 8.67 \\
\hline Muscular belly L-left & 12 & 9.63 & 36.75 & 17.33 & 8.16 \\
\hline Muscular belly W-right & 17 & 1.33 & 5.07 & 2.47 & 0.96 \\
\hline Muscular belly W-left & 12 & 1.64 & 4.38 & 2.27 & 0.77 \\
\hline Tendon L-right & 17 & 15.20 & 29.35 & 20.23 & 4.51 \\
\hline Tendon L-left & 12 & 10.93 & 29.78 & 19.27 & 4.93 \\
\hline Tendon W-right & 17 & 0.26 & 2.42 & 0.86 & 0.52 \\
\hline Tendon W-left & 12 & 0.36 & 2.01 & 0.89 & 0.53 \\
\hline
\end{tabular}

L: length; W: width 


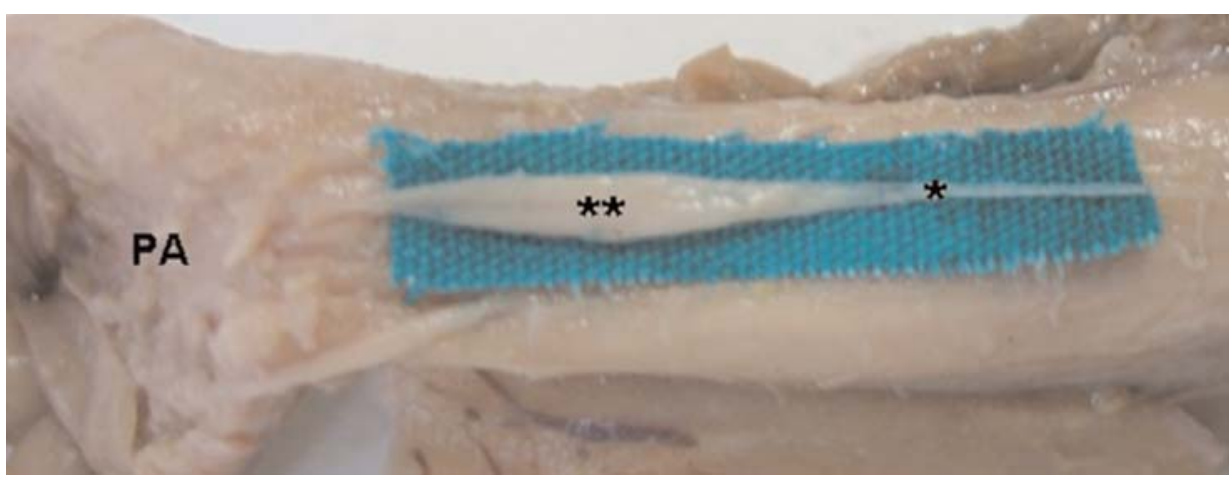

Figure 4. Reversed palmaris longus muscle (right arm). *: tendon; **: muscular belly; ME: medial epicondyle; PA: palmar aponeurosis. reported a much higher prevalence of agenesis $(63.9 \%)$ in the Gaziantep population in Turkey. ${ }^{[14]}$ Studies among the Asian population showed that the incidence is $3.4 \%$ in Japanese ${ }^{[15]} 4.6 \%$ in Chinese, ${ }^{[16]}$ and $0.6 \%$ in the Korean ${ }^{[17]}$ respectively. Within Africa, studies have equally been conducted. Available information showed that the incidence is $1.02 \%$ in an Ugandan population. ${ }^{[18]}$ Absence of palmaris longus muscle varies beetween populations, high rate Ceyhan et al. presented is thought to depend on race characteristics (Table 2).

Most of the morphometric manuscripts published previously presents data about adults. There are only a few studies done in human fetuses. Alagöz et al. reported palmaris longus length $14.70 \pm 2.17$ and width $0.77 \pm 0.20 .^{[23]}$ Stecco et al. mentioned the average length of the muscular belly was $13.8 \mathrm{~cm}$ (SD: $3.4 \mathrm{~cm}$, range: $9.5-23 \mathrm{~cm}$ ), while that of the tendon was $13.1 \mathrm{~cm}$ (SD: $3.3 \mathrm{~cm}$, range: $8.0-15.5 \mathrm{~cm}){ }^{[24]}$ Ito et al. reported palmaris longus length $124.6 \pm 17 \mathrm{~mm}$ and width $4.5 \pm 0.7$ in male, and $108.3 \pm 16.4 \mathrm{~mm}$ and width $4 \pm 0.7$ in female. ${ }^{[25]}$

Kopuz reported bilateral absence in $40.4 \%$ and unilateral absence in $8.5 \%$ and palmaris longus length 41.1 $\mathrm{mm}$ and width $1.7 \mathrm{~mm}$ in fetuses. ${ }^{[19]}$ In our study the palmaris longus muscles were absent in both forearms in 7 $(29.2 \%)$ and in one forearm in $5(20.8 \%)$ fetuses. Most fetuses had a typical palmaris longus muscle and tendon shape. The mean length and width of the tendons in second trimester were $18.42 \pm 9.55$ and $0.66 \pm 0.37 \mathrm{~mm}$, respectively, and in third trimester $25.9 \pm 13.90$ and $1.71 \pm 0.95 \mathrm{~mm}$, respectively. The mean length and width of the muscular belly in second trimester were $13.33 \pm 7.05$ and $2.03 \pm 1,04 \mathrm{~mm}$, respectively, and in third trimester $30.42 \pm 16.81$ and $3.77 \pm 2.07 \mathrm{~mm}$, respectively. As seen in our study, differently from Kopuz, length and width of tendon and muscular parts of muscle measured seperately by dividing in trimesters.

Many authors have reported cases of reversed palmaris longus muscle either as an anatomical variation or as a surgical finding. ${ }^{[4]}$ In some reversed palmaris longus cases; muscle belly can be two ${ }^{[26]}$ or three-headed. ${ }^{[4,10]} \mathrm{We}$ didn't observe two or three-headed muscular belly in our fetuses.

Kopuz observed palmaris longus muscle which had proximal and distal tendons in two cases. In one case; the

Table 2

Prevalence and distribution of palmaris longus agenesis in various authors

\begin{tabular}{lcc}
\hline Authors & $\begin{array}{c}\text { Bilateral absence of } \\
\text { palmaris longus (\%) }\end{array}$ & $\begin{array}{c}\text { Unilateral absence of } \\
\text { palmaris longus (\%) }\end{array}$ \\
\hline Vanderhooft et al. $^{[1]]}$ & $8-16$ & $4-14$ \\
Kayode $^{[13]}$ & 18.75 & 12.5 \\
Ceyhan et al. $^{[14]}$ & 43.2 & 20.7 \\
Eric et al. $^{[17]}$ & 15.9 & 21.6 \\
${\text { Kose et al. } .^{[20]}}_{\text {Harvey et al. }{ }^{[2]]}}$ & 15 & 11.5 \\
Mbaka et al. ${ }^{[22]}$ & 11 & 5.5 \\
Kopuz (fetus) & 1.5 & 5.4 \\
Kocabiyik et al. (fetus) & 40.4 & 8.5 \\
\hline
\end{tabular}


Figure 5. (a) Long muscular belly of palmaris longus muscle (right arm). (b) Long muscular belly of palmaris longus muscle (left arm). *: tendon; **: muscular belly; ME: medial epicondyle; PA: palmar aponeurosis.
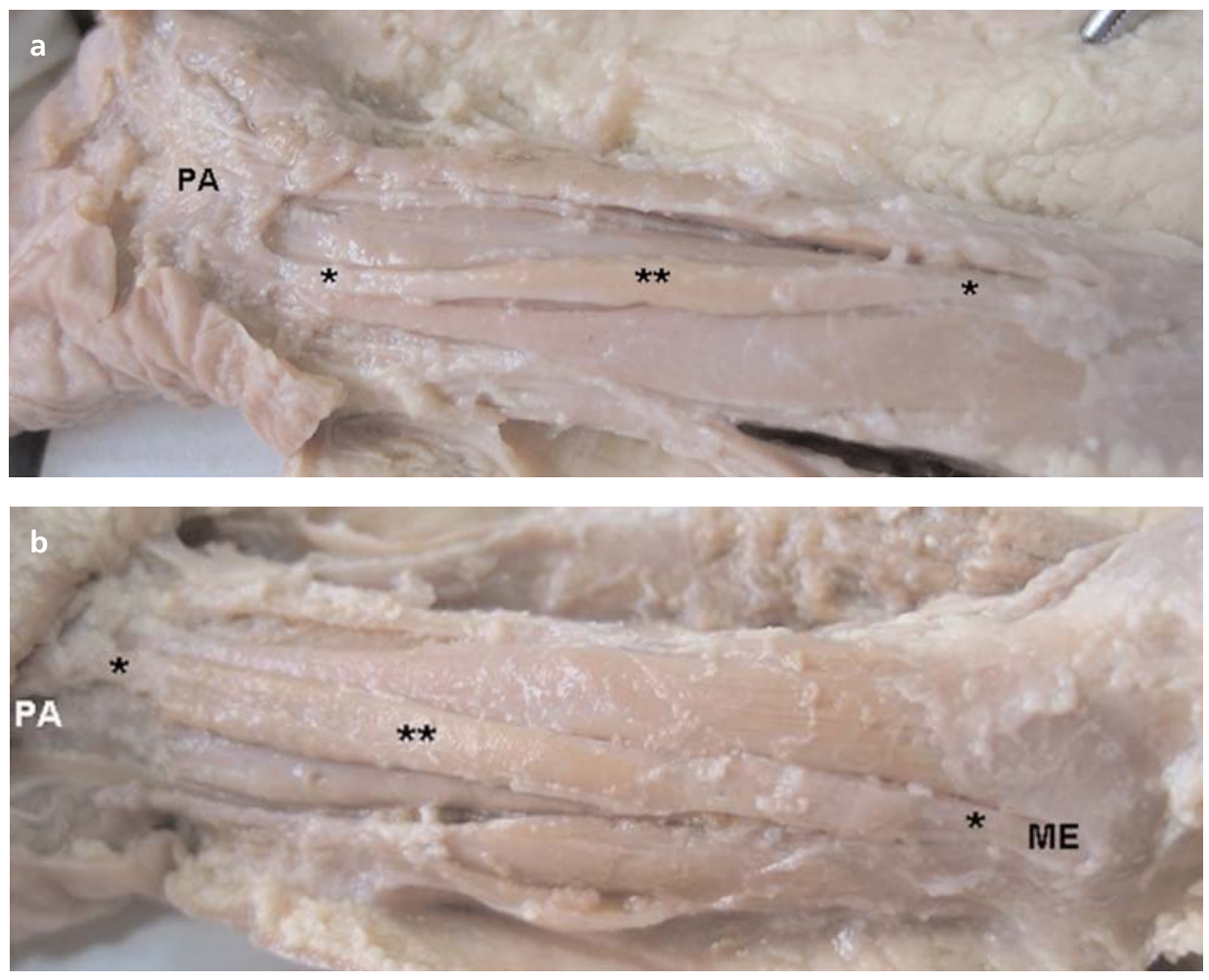

fibers of palmaris longus muscle joined to flexor digitorum superficialis muscle. ${ }^{[19]} \mathrm{We}$ found reversed palmaris longus muscle in 2 forearms in two fetuses. Long muscular belly and short tendon of palmaris longus muscle was observed in one of 24 fetuses, unilaterally but in forearms.

The overuse of the reversed palmaris longus muscle may lead to the muscle's local hypertrophy. According to the literature a reversed palmaris longus muscle may cause a compartment syndrome with pain and edema in the wrist area, the carpal tunnel syndrome, and Guyon's syndrome. The described variation is also useful to the hand surgeons, as the palmaris longus muscle is an anatomical landmark for surgical procedures at this area. ${ }^{[26]}$

The palmaris longus tendon has been proven to be a popular graft at the craniofacial and other areas of surgery because of its ease of harvest and suitability. ${ }^{[27]}$

Tendon of the palmaris longus muscle finds varied use as a donor tendon although the tendon is of little functional use to humans. It is of importance, besides the hand surgeon, to the plastic surgeon, the ophthalmologist $^{[28]}$ as well as the otolaryngologist. ${ }^{[2]]}$ Tendon grafts are frequently needed in reconstructive surgery on the hand. Many surgeons agree that the palmaris longus tendon is the first choice as a donor tendon because it ful- fills the necessary requirements of length, diameter and availability, and can be used without producing any functional deformity. ${ }^{[7]}$ The palmaris longus tendon is often considered the ideal donor for tendon grafts for replacement of the long flexors of the fingers, and of the flexor pollicis longus tendon. ${ }^{[30]}$

Differences between the three age groups (young, middle-aged and old) were not significant; however, the middle-aged and young groups showed a lower rate of palmaris longus presence as compared to old-age group. ${ }^{[17]}$ In our study existence of muscle was lesser in fetuses than adults.

It is obvious that the variations of the palmaris longus muscle are numerous. Although rarely seen, these variations may lead to misinterpretation of an existing muscle as absent. Ultrasonography or MRI would confirm these variations precisely, but it is neither cost effective nor time sparing. ${ }^{[20]}$ Also cadaveric studies should be taken into consideration in order to get more significant results than the physical examination tests often used by clinicians. The absence of the palmaris longus tendon in women is statistically more common than men. Bilateral absence of palmaris longus is statistically frequent than unilateral absence. The prevalence of palmaris longus tendon absence is statistically similar between the body sides. $^{[20]}$ 


\section{Conclusion}

In our study the palmaris longus muscles were absent in both forearms in $7(29.2 \%)$ and in one forearm in 5 (20.8\%) fetuses. The existence of the muscle was lesser in fetuses than adults. Reversed palmaris longus muscle was found in 2 forearms in two fetuses. Long muscular belly and short tendon of palmaris longus muscle was observed in one of 24 fetuses but in both forearms. The results of our study show a relatively high incidence of tendon absence and pointed to more pronounced loss of the muscle on the left side.

This detailed fetal study in relationship to the palmaris longus muscle would be useful for educational dissections, surgical interventions for relevant clinical procedures, and radiodiagnostical evaluations. We believe that every surgeon must be aware of the variations about the palmaris longus muscle which provides a very useful graft in tendon surgery.

\section{References}

1. Standring S (ed.) Forearm. In: Gray's anatomy. The anatomical basis of clinical practice. 40th ed. Edinburgh: Churchill Livingstone Elsevier; 2008. p. 847.

2. Sinnatamby CS. Last's anatomy. Regional and applied. 10th ed. Edinburgh: Churchill Livingstone; 1999. p. 63.

3. Moore KL, Dalley AF. Clinically oriented anatomy. 4th ed. Philadelphia: Lippincott Williams \& Wilkins; 1999. p. 737.

4. Yıldız M, Şener M, Aynacı O. Three-headed reversed palmaris longus muscle: a case report and review of the literature. Surg Radiol Anat 2000;22:217-9.

5. Schlafly B, Lister G. Median nerve compression secondary to bifid reversed palmaris longus. J Hand Surg Am 1987;12:371-3.

6. Atiyeh BA, Hashim HA, Hamdan AM, Kayle DI, Musharafieh RS. Lower reconstruction and restoration of oral competence with dynamic palmaris longus vascularised sling. Arch Otolaryngol Head Neck Surg 1998; 24:1390-2.

7. Troha F, Baibak GJ, Kelleher JC. Frequency of the palmaris longus tendon in North American Caucasians. Ann Plast Surg $1990 ; 25: 477-8$.

8. Schneider LH. Flexor tendons-late reconstruction. In: Green DP, Hotchkiss RN, Pederson WC, editors. Green's operative hand surgery. 4th ed. Edinburgh: Churchill Livingstone; 1999. p. 1898-950.

9. Pai MM, Prabhu LV, Nayak SR, et al. The palmaris longus muscle: its anatomic variations and functional morphology. Rom J Morphol Embryol 2008;49:215-7.

10. Koo CC, Roberts AH. The palmaris longus tendon. Another variation in its anatomy. J Hand Surg Br 1997;22:138-9.

11. Vanderhooft E. The frequency and relationship between the palmaris longus and plantaris tendons. Am J Orthop 1996;25:38-41.
12. Wehbe MA. Tendon graft donor sites. J Hand Surg Am 1992;17:1130-2.

13. Kayode AO, Olamide AA, Blessing IO, Victor OU. Incidence of palmaris longus muscle absence in Nigerian population. Int $\mathrm{J}$ Morphol 2008;26:305-308.

14. Ceyhan O, Mavi A. Distribution of agenesis of palmaris longus muscle in 12 to 15 years old age groups. Indian J Med Sci 1997;51:156-60.

15. Adachi B. Beiträge zur Anatomie der Japaner. XII. Die Statistik der Muskelvarietäten. Zeitsch Morphol Anthropol 1909;12:261-312.

16. Sebastin SJ, Puhaindran ME, Lim AY, Lim IJ, Bee WH. The prevalence of absence of the palmaris longus - A study in a Chinese population and a review of the literature. J Hand Surg $\mathrm{Br}$ 2005;30:525-7.

17. Eriç M, Krivokuça D, Savoviç S, Leksan I, Vuciniç N. Prevalence of the palmaris longus through clinical evaluation. Surg Radiol Anat 2010;32:357-61.

18. Igbigbi PS, Ssekitoleko HA. Incidence of agenesis of the palmaris longus muscle in Ugandans. West African J Anat 1998; 6:21-3.

19. Kopuz C. Yenidoğanlarda m. palmaris longus'un morfolojik olarak incelenmesi. Morfoloji Dergisi 1999;7:6-9.

20. Köse O, Adanır O, Çırpar M, Kürklü M, Kömürcü M. The prevalence of absence of the palmaris longus: a study in Turkish population. Arch Orthop Trauma Surg 2009;129:609-11.

21. Harvey JF, Chu G, Harvey PM. Surgical availability of the plantaris tendon. J Hand Surg 1983; 8:243-7.

22. Mbaka GO, Ejiwunmi AB. Prevalence of palmaris longus absence - A study in the Yoruba population. Ulster Med J 2009;78:90-3.

23. Alagöz MS, Uysal AC, Tüccar E, Tekdemir İ. Morphologic assessment of the tendon graft donor sites: palmaris longus, plantaris, tensor fascia lata. J Craniofac Surg 2008;19:246-50.

24. Stecco C, Lancerotto L, Porzionato A, et al. The palmaris longus muscle and its relations with the antebrachial fascia and the palmar aponeurosis. Clin Anat 2009;22:221-9.

25. Ito MM, Aoki M, Kida MY, Ishii S, Kumaki K, Tanaka S. Length and width of the tendinous portion of the palmaris longus: a cadaver study of adult Japanese. J Hand Surg Am 2001;26:706-10.

26. Georgiev GP, Jelev L. Unusual coexistence of a variant abductor digiti minimi and reversed palmaris longus and their possible relation to median and ulnar nerves entrapment at the wrist. Rom J Morphol Embryol 2009;50:725-7.

27. Çınar C, Arslan H, Ogur S. Reconstruction of massive lower lip defect with the composite radial forearm palmaris longus free flap: empowered static and partial dynamic reconstruction. J Craniofac Surg 2007;18:237-241.

28. Bachelor EP, Jobe RP. The absent lateral canthal tendon: reconstruction using a Y graft of palmaris longus tendon. Ann Plast Surg 1980;5:362-8.

29. Song IC, Bromberg BE. Pharyngo-palatoplasty with free transplantation of the palmaris longus. Br J Plast Surg 1974;27:337-43.

30. Zeybek A, Gürünlüoğlu R, Çavdar S, Bayramiçli M. A clinical reminder: a palmaris longus muscle variation. Ann Plast Surg 1998;41:224-5.

Correspondence to: Necdet Kocabıyık, MD

Department of Anatomy, Gulhane Military Medical Academy

06018, Etlik, Ankara, Turkey

Phone: 00903123043515 Fax: 00903123042150

e-mail: nkocabiyik@gata.edu.tr

Conflict of interest statement: No conflicts declared. 